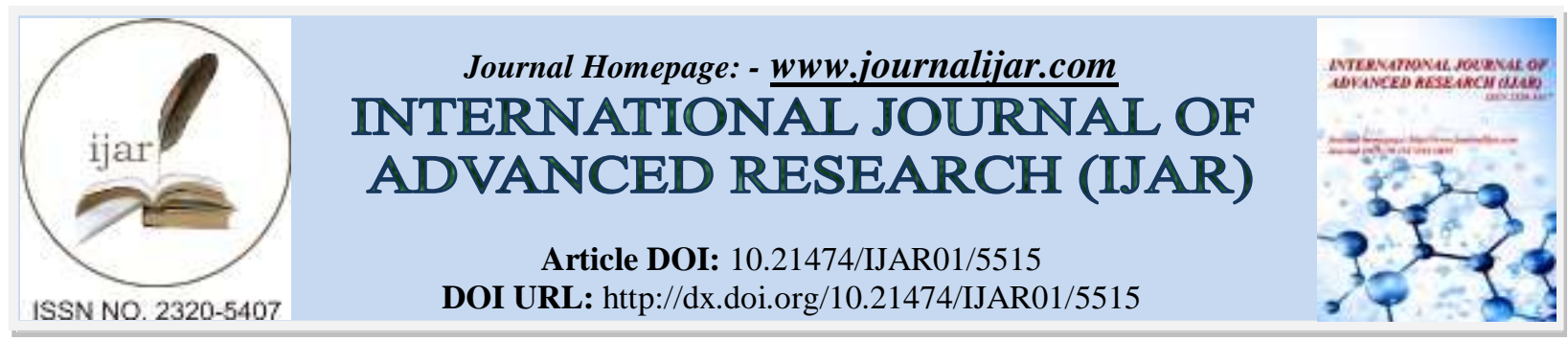

RESEARCH ARTICLE

\title{
GREEN LIQUOR PRETREATMENT FOR THE ENHANCEMENT OF ENZYMATIC SACCHARIFICATION OF RICE HUSK FOR ETHANOL PRODUCTION.
}

\author{
${ }^{*}$ Ajeet Kumar Srivastava ${ }^{1}$, A V Narayan ${ }^{2}$, Narendra Kumar $S^{1}$, Lingayya Hiremath ${ }^{1}$ and Praveen Kumar \\ Gupta ${ }^{1}$. \\ 1. Assistant Professor, Department of Biotechnology, R V College of Engineering, Bangalore, 560059. \\ 2. Associate Professor, Department of Biotechnology, R V College of Engineering, Bangalore, 560059.
}

\section{Manuscript Info \\ Manuscript History \\ Received: 02 August 2017 \\ Final Accepted: 04 September 2017 \\ Published: October 2017}

Key words:-

Lignocellulosic biomass, Enzymatic hydrolysis, green liquor, pretreatment, Ethanol

\begin{abstract}
Lignocellulosic biomass is an attractive renewable resource for future liquid transport fuel. Efficient and cost-effective production of bioethanol from lignocellulosic biomass depends on the development of a suitable pretreatment system. The development of a new, relatively simple process, which uses green liquor (sodium carbonate and sodium sulfide) as a pretreatment for the production of ethanol is described in this article. The enzymatic digestibility of rice husk is enhanced after pretreatment since pretreated solids show significant delignification with high sugar availability. During pretreatment, an increasing temperature leads to enhanced delignification, whereas an increased degradation of polysaccharides as well, of which xylan acts more susceptible than glucan. Thereafter Ethanol production from rice husk by Saccharomyces cerevisiae was investigated through fermentative mechanism. To reach the maximum ethanol production yield, the most important influencing factors in the pretreatment process are including temperature, green liquor concentration, and the pretreatment time . The maximum ethanol obtained from rice husk with Saccharomyces cerevisiae $(12.03 \pm 1.17 \mathrm{~g} / \mathrm{l})$. The cellulose produced by this process can be enzymatically hydrolyzed to monomeric sugars with a high overall sugar recovery using Trichoderma reesei. About 35\% of the lignin is removed during the green liquor pretreatment process, which is sufficient for efficient microbial enzymatic hydrolysis. The amount of sugar produced in microbial enzymatic hydrolysis increased by the green liquor.
\end{abstract}

Copy Right, IJAR, 2017,. All rights reserved.

\section{Introduction:-}

Due to the increasing global population, energy consumption has also increased, and the present fossil fuel resources do not seem to be able to meet the future energy demands in an environmentally-sustainable manner. To address this challenge, biofuels, as renewable, sustainable, and efficient energy resources, have been considered as promising resources. Biofuels, e.g., biogas, biodiesel, ethanol, and hydrogen produced from biomass, are suggested to be suitable future alterative energy resources. Among liquid biofuels, ethanol, as a clean and renewable energy source, has received significant deal of attention (Saha and Cotta, 2008; Karimi and Chisti, 2015). Ethanol can be produced from different raw materials, including sugar-based, starched-based, and lignocellulosic materials (Balat, 2011). 
Using inexpensive raw materials is crucial for the economically-feasible production of ethanol (Brethauer and Wyman, 2010). Lignocellulosic substrates are the most abundant renewable and inexpensive resources on the Earth. It has been frequently reported that agricultural and forest residues are largely unused and available in huge capacity (Kim and Dale, 2004; Limayem and Ricke, 2012; Salehian and Karimi, 2013). For instance, rice is a plant that is widely cultivated in Asia, Africa, and Latin America. The cultivation of rice leads to the production of huge amounts of straw and husk. The husk yield is around $20 \%$ of the rice weight, which is mainly unused (Taherzadeh and Karimi, 2007). Lignin, cellulose, and hemicelluloses are the major constituents of lignocellulosic materials. Cellulose can be enzymatically hydrolyzed to glucose and then fermented to ethanol. However, the presence of lignin and hemicellulose decreases the access of hydrolytic enzymes to cellulose. To increase the enzymes' accessibility, lignin and hemicelluloses should be removed, and the complex structure should be opened up (Taherzadeh and Karimi, 2007). Thus, a pretreatment process is an essential and the most important step in biofuel production from lignocellulosic materials (Srivastava et al.,2012). An effective pretreatment should improve the hydrolysis while least sugar degradation is caused. Several pretreatment methods have been developed such as alkaline and acidic techniques (Taherzadeh and Karimi, 2008; Tabil et al., 2011). The alkaline pretreatments, e.g., by using NaOH, are among the most effective pretreatments (Shafiei et al., 2015., Srivastava et al.,2014 ).

After pretreatment, the pretreated materials can be either separately hydrolyzed and fermented or simultaneously hydrolyzed and fermented (Srivastava et al.,2014). Simultaneous saccharification and fermentation (SSF) is preferred, as the concentration of the released sugar is low, because the released sugars are directly consumed by the microorganisms. This reduces the risk of contamination, and it is also possible to conduct the process with lower enzyme loadings (Wyman, 1994). Saccharomyces cerevisiae is the most common organism used for the fermentation of hexose, while zygomycetes fungi can utilize a wider range of monosaccharides, including pentoses, and are of high performance for ethanol production from lignocellulosic materials (Srivastava et al.,2014). Furthermore, the biomass of these fungi are valuable products with various applications, due to the fact the it contains considerable amounts of glucosamine $(\mathrm{GlcN})$ and essential fatty acids (Chatterjee et al., 2005; Bellou et al., 2012). Glucosamine, an amino monosaccharide, is a major component of the cell wall. Glucosamine has numerous applications, e.g., as a drug for osteoarthritis therapy and as a dietary supplement (Sitanggang et al., 2012; Mohammadi et al., 2013).

Recently, green liquor used as a pretreatment of Kraft pulping or biomass conversion has attracted much attention of some researchers. Their experimental data also confirmed that as a promising pretreatment agent, green liquor results in a higher retention of polysaccharides and increased delignification selec- tivity. Therefore, an enhancement of pulp qualities and competitive sugar recovery of enzymatic hydrolysis can be obtained. Green liquor is mainly composed of sodium carbonate and sodium sulfide. Of which sodium carbonate $\left(\mathrm{Na}_{2} \mathrm{CO}_{3}\right)$, also the main component of green liquor from soda-pulping, is a sort of weak alkali and it generally has no or slight alkaline degradation to lignocelluloses. Though the existence of sodium sulfide $\left(\mathrm{Na}_{2} \mathrm{~S}\right)$ is good for delignification, the elemental sulfur will lead to the complexity of spent liquor handling process as well as environmental contamination if the scale of process is small. China is the largest agricultural country in the world. The huge quantities of agricultural residues, such as corn stover, wheat straw, rice husk, and others, cause serious environmental problems. Bioethanol from these materials is a potential and feasible pathway to solve these troubles. Rice husk can be considered as a novel feedstock for bioethanol production in that it contains significant amount of cellulose and hemicellulose as well as soft carbohydrates (SCs), which are defined as readily recoverable carbohydrates via direct extraction or enzymatic hydrolysis, and these can be readily hydrolyzed into fermentable sugars. So an appropriate pretreatment technique to remove as much lignin as possible while keep most of the structural carbohydrates and unstable SCs is one of the major challenges for bioethanol production from rice husk. Among many pretreatment methods of rice straw, the alkali pretreatment is one of the most widely employed processes. However, a severe alkaline pretreatment may result in a significant loss of carbohydrates. Therefore, the purpose of the present study is to evaluate the effects of sodium carbonate $\left(\mathrm{Na}_{2} \mathrm{CO}_{3}\right)$ pretreatment on the chemical compositions and enzymatic saccharification of rice husk, which is rarely reported in existing literature. 


\section{Materials and Methods:- \\ Substrate, microorganisms:- \\ Raw materials:-}

Rice husk from local mill was ground using a Wiley mill, then the particles between the sizes of 40 and 80 mesh were collected and extracted with benzene- ethanol $(2: 1, \mathrm{v}: \mathrm{v})$ in a Soxhlet apparatus for $24 \mathrm{~h}$. All the weight percentages were calculated based on the oven dry sample.

\section{Microorganisms:-}

Trichoderma reesei (MTCC-4876) were obtained from, MTCC Chandigarh. The fungi produces cellulolytic enzymes that converted carbohydrate polymers into fermentable sugars Later Saccharomyces cerevisiae was inoculated to utilize reducing sugars to ethanol.

\section{Green liquor pretreatment:-}

The pretreatment was carried out in an electrically heated oil bath containing 10 bombs of $1 \mathrm{~L}$ capacity rotated at a speed of $6 \mathrm{r} / \mathrm{min}$. The rice husk was pretreated in duplicate at 120,130, 140, and $150{ }^{\circ} \mathrm{C}$ with green liquor $\left(\mathrm{Na}_{2} \mathrm{CO}_{3}+\mathrm{Na}_{2} \mathrm{~S}\right)$. A solid-to-liquid ratio of 1:6 was applied. Rice husk was first impregnated with $\left(\mathrm{Na}_{2} \mathrm{CO}_{3}+\mathrm{Na}_{2} \mathrm{~S}\right)$ at $80{ }^{\circ} \mathrm{C}$ for $30 \mathrm{~min}$, and then the temperature was raised to the target temperature at a rate of $2{ }^{\circ} \mathrm{C} / \mathrm{min}$. After the target temperature was reached, the pretreatment was terminated immediately by cooling the bombs to room temperature in cold water. The pretreated solid was collected and washed with deionized water until the $\mathrm{pH}$ of the washed liquid was approximately 7.0, and then used for determination of total solid, lignin, ash and polysaccharides prior to enzymatic hydrolysis. The pretreatment spent liquor was collected for $\mathrm{pH}$ analysis.

\section{Culture conditions:-}

$5 \mathrm{~g} / 100 \mathrm{ml}$ (Mandel's medium) of rice husk was taken in conical flask $(250 \mathrm{ml})$. The conical flasks were plugged with cotton and sterilized at $15 \mathrm{lbs}$ per sq.inch for 30 minutes. The flasks were inoculated with the fungal strains in their different concentrations $(\mathrm{ml})$. These flasks were incubated at room temperature for 6 days on an orbital shaker. After six days mycelium was separated by filtration through Whatman filter paper. The filtrate was used for further studies (Thimmaiah S K , 1999)

\section{Determination of total carbohydrate:-}

The carbohydrate content of pretreated raw materials in the culture broth was measured by Anthrone method (Sadasivam S Manickam A., 2006) .

\section{Determination of reducing sugars :-}

Reducing sugars in pretreated raw materials in the culture broth were determined by dinitrosalicylic acid (DNS) method (Miller G. L,1959)

\section{Results and Discussion:-}

The microbial saccharification of all the chemically pretreated substrates showed an improved conversion of cellulose to glucose because of lignin removal during pretreatments. The green liquor $\left(\mathrm{Na}_{2} \mathrm{CO}_{3}+\mathrm{Na}_{2} \mathrm{~S}\right)$ pretreated substrate caused higher microbial saccharification, which could be because of comparatively lower lignin content in the pretreated substrate. Neutralisation method for detoxification was observed to be better than the other employed detoxification strategy. The ability of delignification in pretreatment is probably differs from the lignin properties (content of p-coumaryl derivatives) in various biomass materials. The removal percentages of lignin and ash in rice husk pretreated with green liquor at different temperature. However, the removal of acid soluble lignin increases with the upgoing pretreatment temperature. It means that acid insoluble lignin is stable during auto-hydrolysis, and the reduction of total lignin is mainly caused by the solution of acid soluble lignin. The relatively low $\mathrm{pH}$ of spent liquor at high temperature results in the partial cleavage of a ether bonds in lignin. Ester bonds between hydroxycinnamic acids and lignin or hemicellulose, a benzyl ether linkages cross-linking lignin and hemicellulose are broken, thus increases the porosity of rice husk. What's more, the liberation of lignin and ash can also facilitate the increasing in xylan recovery and reduce the unproductive binding of cellulase to lignin in the sequential enzymatic hydrolysis. Microbial enzymatic hydrolysis is a step involves cleaving the polymers of cellulose and hemicellulose using enzymes in the production of bioethanol. It is usually carried out under mild conditions, i.e., low pressure and long 
retention time. Hydrolysis efficiency of bio- mass increases when combination of enzymes such as cellulase, xylanase and pectinase are employed rather than only cellulase Zhong et al., 2009. Due to the different structures of cellulose and hemicellulose, the main hydrolysis product of cellulose is glucose, whereas hemicellulose gives rise to several pentoses and hexoses. However, porosity (accessible surface area) of biomass, crystallinity of cellulose fiber, high lignin content, as well as cellobiose and glucose can all reduce enzyme accessibility and the yield of hydrolysis Binod et al., 2012. The sugar recovery is calculated by using the yield of each polysaccharide in microbial enzymatic hydrolysis divided by its original content in rice husk. The sugar yield (based on the weight of original rice husk) in enzymatic hydrolysis of rice husk pretreated with green liquor at different temperature.

\section{Conclusion:-}

Lignin and polysaccharides of rice husk pretreated with green liquor $\left(\mathrm{Na}_{2} \mathrm{CO}_{3}+\mathrm{Na}_{2} \mathrm{~S}\right)$ are degrading with the severity of pretreatment conditions. The degradation of xylan is easier than glucan. Rice husk with lower lignin content were more easily hydrolyzed, demonstrating that the presence of lignin in the cell wall limits microbial enzymatic hydrolysis. cellulosic materials holds great potential due to the widespread availability, abundance and relatively low cost. There after green liquor pretreatment Trichoderma reesei used for increasing saccharification value. After saccharification Saccharomyces cerevisiae used for increasing ethanol production.

\section{References:-}

1. Balat, M., 2011. Production of bioethanol from lignocellulosic materials via the biochemical pathway: a review. Energy Convers. Manage. 52(2), 858-875.

2. Bellou, S., Moustogianni, A., Makri, A., Aggelis, G., 2012. Lipids containing polyunsaturated fatty acids synthesized by Zygomycetes grown on glycerol. Appl. Biochem. Biotechnol. 166(1), 146-158.

3. Binod P., Kuttiraja M., Archana M., Usha J.K., Sindhu R., Sukumaran R.K., Pandey A., 2012, High temperature pretreatment and hydrolysis of cotton stalk for producing sugars for bioethanol production, Fuel 92, 340-345.

4. Brethauer, S., Wyman, C.E., 2010. Review: continuous hydrolysis and fermentation for cellulosic ethanol production. Bioresour. Technol. 101(13), 4862-4874.

5. Chitosan from Mucor rouxii.,2005: production and physico-chemical characterization. Process Biochem. 40(1), 395-400.

6. Karimi, K., Chisti, Y., 2015. Future of bioethanol... Biofuel Res. J. 2(1), 147-147.

7. Karimi, K., Pandey, A., 2014. Current and future ABE processes. Biofuel Res. J. 1(3), 77-77.

8. Khaleghian, H., Karimi, K., Behzad, T., 2015. Ethanol production from rice straw by sodium carbonate pretreatment and Mucor hiemalis fermentation. Ind. Crops Prod. 76, 1079-1085.

9. Kim, S., Dale, B.E., 2004. Global potential bioethanol production from wasted crops and crop residues. Biomass Bioenergy. 26(4), 361-375.

10. Limayem, A., Ricke, S.C., 2012. Lignocellulosic biomass for bioethanol production: current perspectives, potential issues and future prospects. Prog. Energy Combust. Sci. 38(4), 449-467.

11. Miller G. L, Use of dinitrosalicylic acid reagent for determination of reducing sugar, Anal. Chem 31: 426-428, 1959.

12. Mohammadi, M., Zamani, A., Karimi, K., 2013. Effect of Phosphate on Glucosamine Production by Ethanolic Fungus Mucor indicus. Appl. Biochem. Biotechnol. 171(6), 1465-1472.

13. Sadasivam S Manickam A, Biochemical methods, New age international publishers, Delhi, 2006.

14. Saha, B.C., Cotta, M.A., 2008. Lime pretreatment, enzymatic saccharification and fermentation of rice hulls to ethanol. Biomass Bioenergy 32(10), 971-977.

15. Salehian, P., Karimi, K., 2013. Alkali pretreatment for improvement of biogas and ethanol production from different waste parts of pine tree. Ind. Eng. Chem. Res. 52(2), 972-978.

16. Shafiei, M., Kumar, R., Karimi, K., 2015. Pretreatment of lignocellulosic biomass, in: Karimi, K. (Ed.), Lignocellulose-based bioproducts. Springer International Publishing, pp. 85-154

17. Sitanggang, A.B., Sophia, L., Wu, H.S., 2012. Aspects of glucosamine production using microorganisms. Int. Food Res. J. 19, 393-404

18. Srivastava Ajeet Kumar, Agrawal Pushpa, Rahiman Abdul.,2014. Delignification of Rice Husk And Production of Bioethanol International Journal of Innovative Research in Science, Engineering and Technology, 3,3,10187-10194 
19. Srivastava Ajeet Kumar, Agrawal Pushpa, Rahiman Abdul.,2014. Pretreatment and production of Bioethanol from different Lignocellulosic Biomass, International Journal of Advanced Research, 2,4, 888-896

20. Srivastava Ajeet Kumar, Agrawal Pushpa.,2012. Microbial Pretreatment of Lignocellulosics materials and production of Bioethanol,Journal of Environmental Research and Development , 7,1A, 375-380

21. Tabil, L., Kashaninejad, M., Adapa, P., 2011. Biomass feedstock pre-processing-part 1: pre-treatment. INTECH Open Access Publisher.

22. Taherzadeh, M.J., Karimi, K., 2007. Acid-based hydrolysis processes for ethanol from lignocellulosic materials: a review. BioResources. 2(3), 472-499.

23. Taherzadeh, M.J., Karimi, K., 2008. Pretreatment of lignocellulosic wastes to improve ethanol and biogas production: a review. Int. J. Mol. Sci. 9(9), 1621-1651.

24. Thimmaiah S K, Standard methods of biochemical analysis, Kalyani Publishers, New Delhi, 1999.

25. Wyman, C.E., 1994. Ethanol from lignocellulosic biomass: technology, economics, and opportunities. Bioresour. Technol. 50(1), 3-15.

26. Zhong C, et al. 2009. Optimization of enzymatic hydrolysis and ethanol fermentation from AFEX-treated rice straw. Appl Microbiol Biotechnol 84(4), 667-76. 